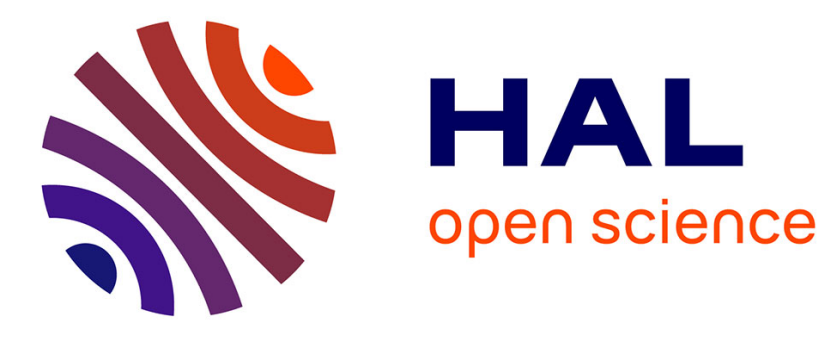

\title{
On-Body Skin Confined Propagation for Body Area Networks (BAN)
}

Qiang Zhang, Julien Sarrazin, Massimiliano Casaletti, Luca Petrillo, Philippe de Doncker, Aziz Benlarbi-Delai

\section{- To cite this version:}

Qiang Zhang, Julien Sarrazin, Massimiliano Casaletti, Luca Petrillo, Philippe de Doncker, et al.. OnBody Skin Confined Propagation for Body Area Networks (BAN). Conference EuCAP 2017, Mar 2017, Paris, France. hal-01511459

\section{HAL Id: hal-01511459 https: / hal.sorbonne-universite.fr/hal-01511459}

Submitted on 3 Sep 2019

HAL is a multi-disciplinary open access archive for the deposit and dissemination of scientific research documents, whether they are published or not. The documents may come from teaching and research institutions in France or abroad, or from public or private research centers.
L'archive ouverte pluridisciplinaire HAL, est destinée au dépôt et à la diffusion de documents scientifiques de niveau recherche, publiés ou non, émanant des établissements d'enseignement et de recherche français ou étrangers, des laboratoires publics ou privés. 


\title{
On-Body Skin Confined Propagation for Body Area Networks (BAN)
}

\author{
Qiang Zhang ${ }^{1,2}$, Julien Sarrazin ${ }^{1}$, Massimiliano Casaletti ${ }^{1}$, Luca Petrillo ${ }^{2}$, Philippe De Doncker ${ }^{2}$, Aziz Benlarbi-Delaï ${ }^{1}$ \\ ${ }^{1}$ Sorbonne Université, UPMC Univ Paris 06, UR2, L2E, F-75005 Paris, France, qiang.zhang@upmc.fr \\ ${ }^{2}$ Université libre de Bruxelles (ULB), Av. Roosevelt 50, 1050 Brussels, Belgium
}

\begin{abstract}
The augmenting need for remote monitoring and treating patients by biophysical sensors interconnected via Body Area Networks (BAN) has recently called researchers' attention. The private and confidential transferred data in such application require high information security. One of the solutions is to use human body as a transmission channel. The body surface-confined transmission restricts the off-body detection, increasing the system security. Also, it reduces the interference between BAN users. For better understanding the body channel propagation mechanism, a lossy multilayered human body model, made of skin, fat, muscle tissues, is established for numeric analysis in this paper, using complex frequency dependent dielectric property for each tissue. Transverse Resonance Method is applied to calculate dispersion and attenuation in the propagation direction up to 60GHz. Since the tissue thickness varies with different localization and different person, 3 skin thicknesses, typically $0.5 \mathrm{~mm}, 1 \mathrm{~mm}$, and $1.5 \mathrm{~mm}$, are considered and compared.
\end{abstract}

Index Terms-Body Area Networks (BAN), propagation, multilayered human body model, dispersion analysis, on-body communication, transverse resonance method.

\section{INTRODUCTION}

With the purpose of improving people's quality of life, the wireless communication systems in the vicinity of human body - Body Area Networks (BAN) - have attracted an increasing attention from researchers in the past decade. IEEE working group is establishing an international standard, defined in IEEE 802.15.6, aiming to provide, shortrange, extremely low power, highly reliable, data rates up to $10 \mathrm{Mbps}$ wireless communications in, on, or around the human body [1].

BAN applications span a wide area, such as personal video and audio devices, body movement detection in interactive games, sport and fitness monitoring, but the use in medical sector is the most involved. One of these innovations leads to the medical remote monitoring and treating in real time using BAN sensors and actuators. Sensors collect patient's various vital signs, such as heart rate, blood pressure, and send them via a cellular network or Internet to analysis center or emergency services, in order to perform the necessary treatment.

Since the transferred data are private and confidential, high information security is required. In BAN, the unbounded nature of wireless communications makes it vulnerable to interception. A robust approach to enhance the security is to ensure it at the physical layer itself, and one of the solutions is to use the human body as a transmission channel. The body surface-confined transmission restricts the off-body detection, thereby increasing the system security. Also, it reduces the interference between BAN users. To date, propagation at few $\mathrm{GHz}$ between on-body sensors have been mostly studied as a space wave interacting with human tissues using either Sommerfeld integral-based theory [2-3] for flat part of the human body, or creeping wave formulation [4-5] for curved parts. The confinement of onbody surface waves inside the human skin has not been paid much interest. One can cite the work in [2], where authors used Transverse Resonance Method (TRM) to determinate the wave propagation in the multilayered human tissues, but no physical insights have been given and the studied band covered only up to $11.5 \mathrm{GHz}$. To better understand how surface wave may be confined in the human skin and to check whether this behavior could be used as a transmission mechanism between on-body sensors, a semi-infinite flat multilayered human model, made of skin, fat, and muscle, is established and presented in section II. The propagation modes, dispersion, and path loss are calculated, using TRM. Matlab simulations results are presented in section III, considering different skin thicknesses. Conclusion and perspectives are given in section IV.

\section{MULTILAYERED HUMAN BODY MODEL}

Human body can be considered as a multilayered structure with different tissues, such as skin, fat, and muscle. Each tissue has a frequency dependent dielectric property, characterized by a complex permittivity $\varepsilon_{c}=\varepsilon_{0} \varepsilon_{r}=$ $\varepsilon_{0}\left(\varepsilon_{r}^{\prime}-j \varepsilon_{r}^{\prime \prime}\right)=\varepsilon_{0} \varepsilon_{r}^{\prime}-j \varepsilon_{0} \varepsilon_{r}^{\prime \prime}$, where $\varepsilon_{0}$ is the vacuum permittivity and $\varepsilon_{\mathrm{r}}$ is the body tissue relative permittivity. Permittivity values for skin, fat, and muscle can be found in [6] at frequencies ranging from $10 \mathrm{~Hz}$ up to $100 \mathrm{GHz}$. The thickness of tissue varies with different localization and different person: skin thickness may range from 0.1 to $5 \mathrm{~mm}$, and fat from 1 to $30 \mathrm{~mm}$ [7-9]. In most human part such as forearm and chest, skin thickness is about $1 \mathrm{~mm}$. In this paper, various skin thicknesses, typically $0.5 \mathrm{~mm}, 1 \mathrm{~mm}$, and $1.5 \mathrm{~mm}$, are considered and compared in calculations to show its influence on propagation. 
Different multilayered models are studied (e.g. air/skin/fat, air/skin/fat/muscle and so on). The 4 layers air/skin/fat/muscle model is presented in Fig. 1, whose dimensions along $\mathrm{y}$-axis and $\mathrm{z}$-axis are supposed infinite, in order to simplify the mode calculation. Outmost layers are also supposed infinite in the transverse direction (x-axis). Intrinsic wavenumber in each layer $\mathrm{k}_{\mathrm{r}}$ is determined as $k_{r}=$ $\omega \sqrt{\varepsilon_{0} \varepsilon_{r} \mu_{0}}$ and can be decomposed into a transverse component $\mathrm{k}_{\mathrm{t}}$ and a $\mathrm{z}$-axis component (propagation direction) $\gamma=\alpha+j \beta$, where $\alpha$ is the attenuation constant and $\beta$ the propagation constant.

To satisfy the propagation condition, $\gamma$ should be identical in all layers. Knowing $\varepsilon_{r_{-} \text {skin }}$ is greater than $\varepsilon_{r_{-} \text {air }}$ and $\varepsilon_{\mathrm{r} \text { fat }}$, and the muscle layer is supposed as an infinite layer in the transverse direction, propagated wave will be mostly confined in the skin, as indicated by red arrows in Fig. 1, forming a stationary wave situation in transverse direction, while in the outer tissues (air and fat), the wave has an exponential transverse decay. Hence, the transverse propagation constant $\mathrm{k}_{\mathrm{t}}$, calculated by $k_{t}=\sqrt{k_{r}^{2}-\gamma^{2}}$, should satisfy the transverse resonance condition for a propagation mode to exist. The transverse impedance is given by $Z_{T M}=\frac{k_{t}}{\omega \varepsilon_{0} \varepsilon_{r}}$ for TM mode and $Z_{T E}=\frac{\omega \mu_{0} \mu_{0}}{k_{t}}$ for TE mode. To find the propagation modes, TRM [10-11] is used and a transmission line model such as in Fig. 1 is therefore considered. The following condition has to be satisfied: $Z_{\text {air }}+Z_{\text {_brought }}=0$ for a mode to be established. Complex solutions $\gamma$ of these complex equations have been found numerically in Matlab in order to plot dispersion diagram up to $60 \mathrm{GHz}$, with a $500 \mathrm{KHz}$ sample step. Obtained results have been cross-checked with full-wave analysis conducted by CST simulations.
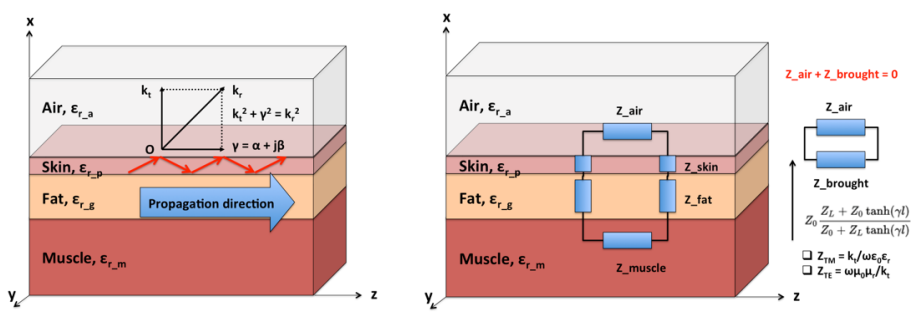

Fig. 1. Multilayered human body modeling (left) and Transverse Resonance Method (right)

\section{RESULTS AND DISCUSSION}

Fig. 2 shows dispersion curves of fundamental propagation modes for air/skin/fat/muscle model with tissues considered in both lossless and lossy cases. Skin thickness is taken as $1 \mathrm{~mm}$ and fat thickness as $13 \mathrm{~mm}$. In the lossless case, where the imaginary part of the complex tissue permittivity is neglected, the TE mode (electric field normal to the plane of incidence, plane $\mathrm{x}-\mathrm{z}$ ) starts propagating at about $3 \mathrm{GHz}$. The TM mode (magnetic field normal to the plane of incidence) is first found at about $18 \mathrm{GHz}$. By taking into account dielectric losses, so using the tissue complex permittivity, the propagation constant $\beta$ becomes larger than the lossless case for each mode.

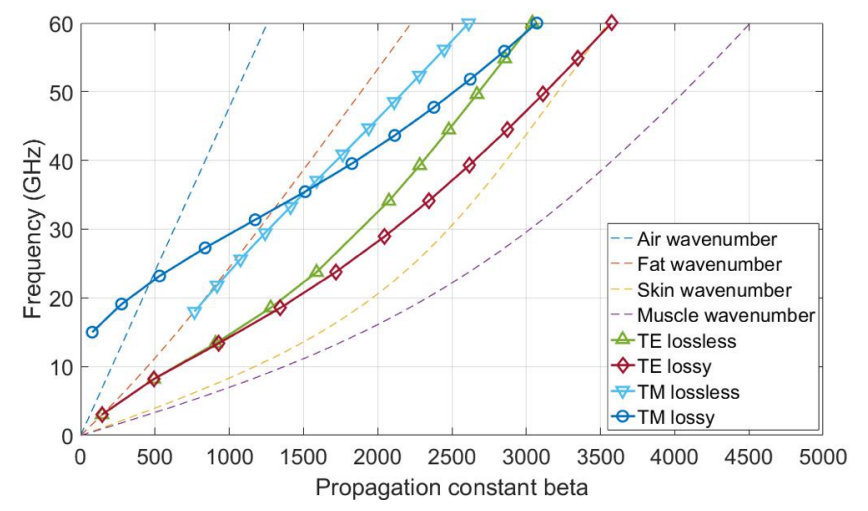

Fig. 2. Propagation constant curves for multilayered human body model (1 mm skin thickness model)

Fig. 3 shows the attenuation along the direction of propagation for the same $1 \mathrm{~mm}$ skin model, while taking into account dielectric losses. The fundamental TE mode exhibits the lowest attenuation for frequencies below $6 \mathrm{GHz}$ (less than $6 \mathrm{~dB} / \mathrm{cm})$. As the frequency increases, its propagation attenuation becomes significantly larger. In addition, the fundamental TM mode (TM lossy (1)) is found to always have large attenuation (about $200 \mathrm{~dB} / \mathrm{cm}$ ). Its attenuation drops to the minimal value at $32 \mathrm{GHz}$, near its mode cutoff frequency.

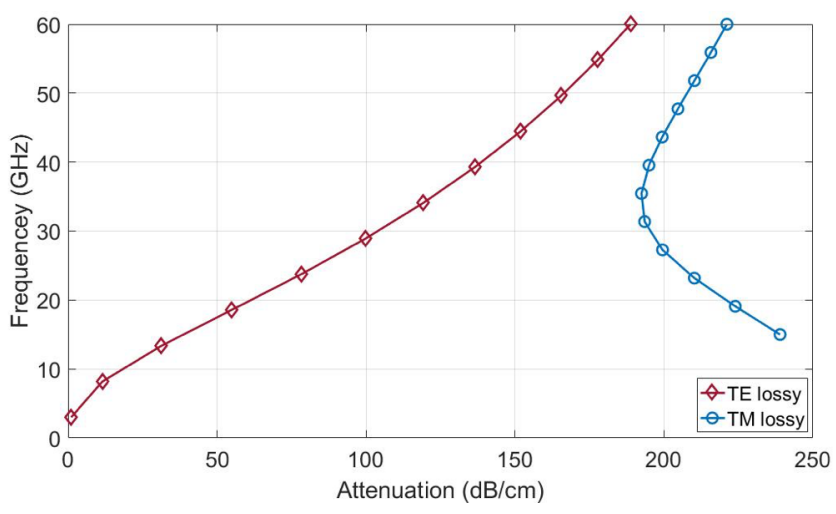

Fig. 3. Attenuation curves for multilayered human body model in lossy case (1 mm skin thickness model)

Table I shows the propagation constant and attenuation constant values for the fundamental TE modes considering different skin thicknesses $(0.5 \mathrm{~mm}, 1 \mathrm{~mm}$, and $1.5 \mathrm{~mm})$ from $2.4 \mathrm{GHz}$ to $60 \mathrm{GHz}$. As expected, lower cutoff frequency is found for larger skin thickness model. Also, for a given frequency, the larger skin thickness, the greater the attenuation. No TM mode was found for $0.5 \mathrm{~mm}$ skin thickness model. 
Furthermore, thicker skin allows more propagation modes existing. Higher order TE and TM modes are found in $1.5 \mathrm{~mm}$ skin thickness model, at $30 \mathrm{GHz}$ and $60 \mathrm{GHz}$ respectively. But these higher order modes always exhibit larger attenuation values than fundamental ones.

One can notice that reasonable attenuation values are found at frequencies below $10 \mathrm{GHz}$ for TE fundamental mode (e.g., $2.3 \mathrm{~dB} / \mathrm{cm}$ at $6 \mathrm{GHz}$ for $0.5 \mathrm{~mm}$ skin model, 2.2 $\mathrm{dB} / \mathrm{cm}$ at $4 \mathrm{GHz}$ for $1 \mathrm{~mm}$ skin model, and $1.1 \mathrm{~dB} / \mathrm{cm}$ for 1.5 mm skin model), which suggests that a skin surface wave propagation could be used for short range on-body propagation while exhibiting confinement properties that are important for privacy issues as well as to reduce inter-BAN interferences.

TABLE I. TE MODE PROPAGATION CONSTANT AND ATTENUATION FOR DIFFERENT SKIN THICKNESS FROM 2.4GHZ TO 60GHZ

\begin{tabular}{|c|c|c|c|c|c|c|}
\hline \multirow{3}{*}{$\begin{array}{c}\text { Freque } \\
\text { ncy } \\
(\mathbf{G H z})\end{array}$} & \multicolumn{6}{|c|}{ Skin thickness } \\
\hline & \multicolumn{2}{|c|}{$0.5 \mathrm{~mm}$} & \multicolumn{2}{|c|}{$1 \mathrm{~mm}$} & \multicolumn{2}{|c|}{$1.5 \mathrm{~mm}$} \\
\hline & $\begin{array}{c}\text { Propaga } \\
\text { tion } \\
\text { constant } \\
\beta \\
\end{array}$ & $\begin{array}{c}\text { Attenua } \\
\text { tion } \\
(\mathrm{dB} / \mathrm{cm})\end{array}$ & $\begin{array}{c}\text { Propaga } \\
\text { tion } \\
\text { constant } \\
\beta \\
\end{array}$ & $\begin{array}{c}\text { Attenua } \\
\text { tion } \\
(\mathrm{dB} / \mathrm{cm})\end{array}$ & $\begin{array}{c}\text { Propaga } \\
\text { tion } \\
\text { constant } \\
\beta \\
\end{array}$ & $\begin{array}{c}\text { Attenua } \\
\text { tion } \\
(\mathrm{dB} / \mathrm{cm})\end{array}$ \\
\hline 2.4 & - & - & - & - & 117 & 1.1 \\
\hline 4 & - & - & 195 & 2.2 & 223 & 3.4 \\
\hline 6 & 275 & 2.3 & 324 & 5.7 & 394 & 7.9 \\
\hline 8 & 368 & 5.3 & 477 & 10.9 & 588 & 14.0 \\
\hline 10 & 470 & 9.4 & 643 & 17.7 & 789 & 21.4 \\
\hline 20 & 1011 & 43.5 & 1454 & 61.5 & 1693 & 65.1 \\
\hline 30 & 1502 & 83.7 & 2110 & 104.1 & 2374 & 106.1 \\
\hline 40 & 1949 & 119.5 & 2652 & 138.8 & 2919 & 139.4 \\
\hline 50 & 2374 & 149.3 & 3131 & 166.5 & 3394 & 166.1 \\
\hline 60 & 2789 & 173.9 & 3574 & 188.8 & 3831 & 187.8 \\
\hline
\end{tabular}

\section{CONCLUSION}

Multilayered analytical human body model was used to study skin surface wave on-body. Skin confined propagation mode dispersion and attenuation were analyzed for different skin thickness models. Reasonably low propagation loss values were found at lower frequencies (typically below 10 $\mathrm{GHz}$ ). As perspectives of this work, on-body surface wave launchers will be investigated in order to verify whether the identified suitable propagation modes can be efficiently excited.

\section{REFERENCES}

[1] "IEEE Standard for Local and metropolitan area networks - Part 15.6: Wireless Body Area Networks," IEEE Std 802156-2012, pp. 1-271, Feb. 2012.

[2] A. Lea, P. Hui, J. Ollikainen, and R. G. Vaughan, "Propagation Between On-Body Antennas," IEEE Trans. Antennas Propag., vol. 57, no. 11, pp. 3619-3627, Nov. 2009.

[3] N. Chahat, G. Valerio, M. Zhadobov, and R. Sauleau, "On-body propagation at $60 \mathrm{GHz}$," IEEE Trans. Antennas Propag., vol. 61, no. 4, pp. 1876-1888, Apr. 2013
[4] T. Alves, B. Poussot, and J. M. Laheurte, "Analytical propagation modeling of BAN channels based on the creeping-wave theory," IEEE Trans. Antennas Propag., vol. 59, pp. 1269-1274, 2011.

[5] L. Petrillo, T. Mavridis, J. Sarrazin, D. Lautru, A. Benlarbi-Delaï and P. De Doncker, "Analytical Creeping Wave Model and Measurements for $60 \mathrm{GHz}$ Body Area Networks," IEEE Transactions on Antennas and Propagation, vol. 62, no. 8, pp. 4352-4356, Aug. 2014

[6] "Dielectric Properties of Body Tissues: Home page." [Online]. Available: http://niremf.ifac.cnr.it/tissprop/.

[7] M. M. Black, "A Modified Radiographic Method for Measuring Skin Thickness*,” Br. J. Dermatol., vol. 81, no. 9, pp. 661-666, Sep. 1969.

[8] H. Alexander and D. L. Miller, "Determining Skin Thickness with Pulsed Ultra Sound,” J. Invest. Dermatol., vol. 72, no. 1, pp. 17-19, Jan. 1979.

[9] R. Marks, P. J. Dykes, and E. Roberts, "The measurement of corticosteroid induced dermal atrophy by a radiological method," Arch. Dermatol. Res., vol. 253, no. 2, pp. 93-96.

[10] D. M. Pozar, Microwave Engineering. Wiley, 2004.

[11] C. A. Balanis, Advanced Engineering Electromagnetics. New York: John Wiley \& Sons, 1989. 